\title{
Nietzsche e as consequências $^{*}$
}

\author{
Otto Maria Carpeaux ${ }^{* *}$
}

Resumo: Na tentativa de compreender o dilema entre "os valores da civilização alemã e as forças destruidoras no seio do mesmo povo que os criou", Carpeaux refuta três teorias então vigentes e considera Nietzsche, o "Dionísio Crucificado", como aquele que experimentou e antecipou as forças contraditórias do espírito alemão. Após fazer um balanço dos mal-entendidos em torno da recepção de Nietzsche tanto na Alemanha quanto na Europa até o ano de 1942, o autor então parte da tese de que o pensador alemão seria simultaneamente poeta, filósofo e profeta, algo que somente seria possível no interior de um "homo religiosus", daquele que vivenciaria o conflito oriundo da antiga barbárie nórdica e da barbárie dos novos burgueses alemães. Dotado de um intelecto que possuía uma "estrutura heraclítica", tal como o de Hegel, Nietzsche, no entanto, na qualidade de "profeta do niilismo europeu", teria não somente descoberto "a estrutura heraclítica do espirito alemão", mas, sobretudo "o caminho da autodestruição deste espírito". Ou seja, antecipado "o caminho do nacionalismo e do socialismo à fusão no nacional-socialismo". Palavras-chave: Nietzsche - espírito alemão - conflito niilismo- nazismo.

\begin{abstract}
A nenhum homem sério poderia deixar de preocupar a grave discrepância entre os valores da civilização alemã e as forças destruidoras no seio do mesmo povo que os criou. A civilização, a nossa e a universal, seria estropiada, se lhe faltassem o sério da consciência de Lutero, a catedral invisível de Bach, o céu olímpico de Goethe, a visão histórica de Hegel, e tantos outros; o que importa não são as obras de alguns gênios, é o espirito que

\footnotetext{
* Publicado no Correio da Manhã. Domingo, 26 de Abril de 1942, p. 1 e 4.

** Otto Maria Carpeaux (1900-1978). Ensaísta e crítico literário austríaco, naturalizado brasileiro. É autor de diversas obras, entre elas a Cinza do Purgatório (1942) e História da Literatura Ocidental (1947), em oito volumes.
}

Cad. Nietzsche, Guarulhos/Porto Seguro, v.37, n.3, outubro/dezembro, 2016. |69 
Maria Carpeaux, $\mathrm{O}$.

os criou, o espirito alemão. Mas a força alemã pretende destruir a nossa civilização, e empreende a cruzada em nome desse mesmo espirito alemão. Estamos diante dum dilema gravíssimo.

Oferecem-se-nos três soluções: os valores da civilização alemã seriam a justificação espiritual bastante da obra material que aqueles empreendem; ou, os próprios valores da civilização alemã seriam os criadores espiritualmente responsáveis daquela força destruidora; enfim, haveria duas Alemanhas, uma divina, outra do diabo, ocupadas numa milenária luta interior a que assistimos, espectadores compassivos e complacentes. Nenhuma dessas três soluções satisfará ao presumido homem sério. São soluções de propagandas banais. A "justificação espiritual" do esforço alemão começou com o extermínio do próprio espirito alemão, extermínio mais radical do que o mundo, em geral, imagina. Doutro lado, o espírito é integral, indivisível, e a luta contra o "perigoso espírito alemão" degeneraria inevitavelmente em luta contra o espírito em geral, que é sempre incômodo. Enfim, a "luta das duas almas no peito" é coisa comum entre as nações e os homens, herança dolorosa de nossa natureza: tem a tristeza banal, a banalidade metafísica de uma tragédia que se repete todos os dias, e atinge força simbólica só nesses poucos heróis sofredores que lutam um combate representativo, num apóstolo Paulo, num Michelangelo, num Pascal, num Friedrich Nietzsche. O próprio Nietzsche soube-o vagamente: nomeou-se a si mesmo "Dionísio crucificado", na noite de sua loucura, - da loucura que predissera a toda a humanidade. Mas o seu sacrifício representativo era em vão: há no mundo uma força mais poderosa do que o espírito, o sofrimento e a própria loucura: é o símbolo terrestre do infinito, a tolice humana.

Nietzsche foi sempre mal-entendido, até pelos seus conterrâneos. A sua apostasia de Wagner, verdadeiro filósofo oficial do Reich Guilhermino, fê-lo intolerável aos universitários e exigiu sua eliminação científica. Encarregaram-se disso os psiquiatras, negando-lhe, de Moebius a Bumm, a validade do pensamento 
"dum professor louco"; esqueciam, os professores com saúde, que a residência de Nietzsche na casa dos alienados é já o julgamento do mundo, onde o psiquiatra é o dono da casa. A oposição da Alemanha imperial contra Nietzsche suscitou, doutra parte, a oposição dos liberais: Brandes proclama-o modelo do "bom Europeu", e os jornais judeus frisam o antibismarckianismo e filosemitismo de Nietzsche. Regozijam-se, com ele, da vida, reconhecem-no, com George Simmel, como vencedor do pessimismo schopenhaueriano, festejam-no, com Max Scheller como restaurador das forças vitais; estão muito satisfeitos quando o grande poeta Stefan George, fundador dum aristocratismo espiritual, bem nietzschiano, admite muitos judeus ao seu "Círculo George". Há, nesse círculo, muitos estudantes universitários, e deve-se a eles a recuperação de Nietzsche para a força vital alemã. Pequenos círculos da burguesia já tinham mal entendido Nietzsche como patrão do nudismo ou de reformas alimentícias. Os filhos descobrem um meio mais eficaz da revitalização alemã: a guerra. Os estudantes-voluntários da batalha de Langemarck, no outono de 1914, morriam com versos de Nietzsche nos lábios. Na República de Weimar, o "NietzscheArchiv" de Weimar é já um centro nacionalista. Para Alfred Bauemler, filósofo oficial do nacional-socialismo, Nietzsche é um "Siegfried", um "alemão rebarbarizado". Friedrich Nietzsche acaba como, para os alemães, começara: um professor secundário com raiva louca.

Se esses mal-entendidos germânicos constituem assunto duma comédia, o mal-entendido de Nietzsche no estrangeiro é mais triste. Os simbolistas que introduziam Nietzsche na França não se davam conta das diferenças entre Nietzsche e Wagner. Os mesmos círculos wagnerianos fascinavam-se com o estilo de Nietzsche e o Zaratustra, que na Alemanha oferecera o programa duma sinfonia de Richard Strauss, tornou-se na França assunto duma grande ópera. O esteticismo confundiu Nietzsche com Oscar Wilde e deduziu daquele um falso imoralismo, mal-entendido nietzschiano 
Maria Carpeaux, $\mathrm{O}$.

de que o próprio Gide não pode ser absolvido. Não faltam tiradas nietzschianas nos romances de d'Annunzio e na boca dos jovens libertinos russos de Artsybachev, sem se lembrarem de que "toda religião de beleza degenera em orgia". Os gritos dos jovens Siegfrieds nietzschianos na batalha de Langemarck perturbavam desagradavelmente esses prazeres, e desde então passou Nietzsche pelo filósofo do pangermanismo bárbaro. Até que os êxitos incontestáveis dessa revitalização alemã perturbaram os próprios cérebros franceses, e a nova geração dos Maulnier e dos Brasillach celebra em Nietzsche o rebarbarizador da Europa.

Donde esses mal-entendidos? Nietzsche não é um autor difícil. É o estilista mais latino e mais claro da língua alemã. A sua prosa é a do grande poeta, que era. Exprime com a mesma maestria o lirismo modesto e profundo dos alemães, a claridade irônica dos latinos, o grande pathos da Bíblia; a sua língua soa como os aforismos densos dos filósofos pré-socráticos, como as canções, ébrias de luz, dos provençais, e às vezes, como versículos mágicos das escrituras sagradas do Oriente. Mas é sempre clara, bastante clara para esconder sob a virtuosidade dos meios estilísticos as contradições internas. Nietzsche é o último filho da "velha Alemanha" humanista, filho espiritual de Goethe e Hölderlin; e no mesmo tempo profere fanfarras duma ébria vontade de dominação, que se perderam no reino sóbrio de Bismarck, e não tiveram eco senão muito mais tarde. Nietzsche é um inimigo mordaz dos alemães - a expressão "bom Europeu" é dele - e ao mesmo tempo proclama o individualismo germânico, o amoralismo bárbaro dos gigantes da "Edda". Nietzsche foi o inimigo mais odioso que o cristianismo jamais teve; mas esse filho de gerações de pastores luteranos sofre intimamente de conflitos religiosos e é, afinal, um cristão pascaliano. Karl Jaspers chama a obra de Nietzsche "um campo de ruinas, coberto de destroços contraditórios". O único laço que lhes dá coerência é a paixão intelectual de Nietzsche, que lembra as personagens de Dostoievski; é a sua personalidade, agitada nas 
profundezas da existência humana, o laço apaixonado de toda a sua personalidade, o que faz da sua loucura a sua obra máxima. Lembra a verdade dos antigos que os poetas são uns delirantes. Friedrich Nietzsche era poeta.

Percebeu-se isto muito cedo, quando o espírito do poeta ainda anoiteceu na casa dos alienados: após a diagnose "loucura" dos psiquiatras, a diagnose "poeta" era a tentativa dos estetas, para se subtraírem as verdades desagradáveis do pensador. Pois filósofo era também, e não menos autêntico. As descobertas psicológicas de Nietzsche, sobre o ressentimento dos fracos e batidos como origem da moralidade, sobre o elemento teatral, o "elemento ator", em todo artista, as suas diagnoses da decadência e do niilismo da civilização moderna, até as suas tentativas duma metafísica da transformação eterna, última metafísica niilista e desesperadamente otimista, que lembra a mais velha metafísica, a de Heráclito: não são poemas. A única obra puramente poética de Nietzsche, o "Zaratustra", é a mais fraca. O poeta Nietzsche chega ao cume, onde a força da palavra poética contém uma inteligência existencial e profundamente verdadeira. Nietzsche parece poeta, porque a sua filosofia se dirige não só ao intelecto, mas a todo o nosso ser. A sua filosofia, em que Karl Jaspers identificou a primeira filosofia existencialista, coloca-nos diante de perguntas ameaçadoras. A diagnose "poeta" não serve para nos subtrairmos aos problemas existenciais que o pensamento nietzschiano nos propõe. Esse poeta autêntico é um autêntico pensador.

Nietzsche é poeta e filósofo ao mesmo tempo. União muito rara e que não deve ser confundida com os balbucios pseudo-filosóficos do poeta Hugo ou com os ócios poéticos do filósofo Santayana. A verdadeira união desses elementos só é possível no fundo agitado da alma dum "homo religiosus". Nasce então um profeta. Friedrich Nietzsche era um profeta.

Mas o que é um profeta? Um homem inspirado por Deus? Ou simplesmente o portador duma verdade que os homens não querem 
Maria Carpeaux, $\mathrm{O}$.

ouvir? Uma definição, mais e menos ampla ao mesmo tempo, diria: um profeta anuncia a uma situação temporal uma verdade eterna. Nietzsche não era um inspirado de Deus nem um sábio que tem razão contra o seu tempo. Era menos e mais. Tinha uma verdade existencial a proferir, como Jeremias antes da destruição do templo, como Isaías antes do advento do Messias. O templo de Nietzsche foi destruído, e o messias "super-homem", com que sonhava, veio. Mas a profecia não pode ser entendida antes do seu cumprimento. Nietzsche não foi mal entendido; ele não podia ser entendido antes do tempo, que é o tempo presente. Nisto reside a sua qualidade profética. Para nós outros, já é tempo de situá-lo no seu tempo passado, para melhor compreender o nosso tempo presente.

A vida independente de Nietzsche começa em 1868, quando o precoce de 24 anos é feito professor de filologia clássica na Universidade de Basiléia. A profissão é significativa: o jovem Nietzsche é um representante da "velha Alemanha" humanística, cheio de Goethe, encantado com os versos de Hölderlin. Filólogos vivem no passado, que para eles é vivo; o seu mundo espiritual não conhece a morte. Nietzsche não conheceu a morte do seu mundo humanístico. Não sabia mesmo da última fase desse humanismo: o pensamento anti-histórico de Schopenhauer escondeu-lhe, e a tantos contemporâneos, a dialética de Hegel, que estava então sendo esquecido. Portanto, o fim da "velha Alemanha" e o advento do Reich de Bismarck não podiam ser compreendidos pela dialética histórica; foram sentidos como catástrofe espiritual, encarada com desesperado pessimismo schopenhaueriano.

Nietzsche espera a salvação na obra poética e musical do schopenhaueriano Wagner, pretensa pedra fundamental duma nova civilização alemã. Em Bayreuth, Nietzsche colheu os primeiros ensinamentos sobre a psicologia "mimética" do artista: reconhece em Wagner o ator, e na sua arte profundamente insincera uma teologia do ilusionismo. Pela primeira vez, o ódio da nova Alemanha o prende. 
Retira-se para a Suíça, onde o suave pessimismo histórico do velho humanista Burckhardt o consola e lhe abre o mundo do humanismo europeu, que não é idêntico ao humanismo alemão. Reformado por motivo de doenças um pouco misteriosas, vive da sua pensão e de algumas rendas pessoais, em Nice, Monte Carlo, Gênova, Veneza. Descobre o mundo latino, sente a fascinação do sol mediterrâneo, da psicologia de Stendhal, da música de Bizet. Não sabe que está possuído da "nostalgia do Sul", bem germânica, saudade insaciável duma pátria irreal, nova espécie da "flor azul" de Novalis, que o romântico incurável Nietzsche sempre amou.

Nietzsche apenas imaginava ser um espírito latino. Nunca podia tornar-se um pagão grego; tinha uma alma cristã, mal disfarçada. Dessa contradição profunda provém o saber de Nietzsche a respeito das "máscaras", e todas as suas descobertas psicológicas. Atrás da máscara cristã de Wagner reconhece o paganismo interior dos alemães, mal cristianizados. A doença moral do próprio Nietzsche advém da luta interna entre o cristianismo da alma e um atavismo pagão. Andreas Heusler mostrou, num estudo profundo, que a desorientação neobárbara de Nietzsche, alma "naturaliter christiana", não tem nada com as máscaras de ópera pseudogermânicas de Wagner, mas resulta dum atavismo real do paganismo nórdico. $\mathrm{O}$ cristão Nietzsche queria ser um pagão mediterrâneo, sulino; e achou em si a barbárie nórdica, germânica. No fundo, porém, Nietzsche só desempenha, e desesperadamente, o papel do bárbaro. É a última máscara. Não pode ser bárbaro: está gravemente doente.

Estamos no centro do problema. A barbárie, de que Nietzsche pretendia ser o profeta, é um fato real. No entanto, não é a barbárie dos velhos valentões germânicos, mas a barbárie dos novos burgueses alemães, no seu novo Reich militar e burguês, meio feudal e meio industrializado. Nietzsche, que sabia pouco da sociologia, descobre, nessa altura, uma verdade pessoal, existencial: a sua própria existência de professor reformado, 
Maria Carpeaux, $\mathrm{O}$.

que vive, em Nice e na Itália, das suas rendas, é uma existência burguesa, relativamente luxuosa. A existência ideal dos "senhores" nietzschianos tem certas premissas econômicas. A existência do próprio Nietzsche não é uma exceção; mas está baseada na doença, que o torna um rendeiro ocioso. Nietzsche não recua nunca diante duma verdade - e da generalização dela: a sua doença revelalhe a base doente de toda a civilização burguesa, o fenômeno da decadência europeia. Apoderando-se das sugestões de Bourget, denuncia o enfraquecimento dos instintos vitais pelo racionalismo burguês. Ataca incessantemente o representante simbólico desse racionalismo: Sócrates. Redescobre os filósofos pré-socráticos, e, entre eles, o maior, o seu mestre: Heráclito, o filósofo da transformação eterna. A estrutura heraclítica do próprio intelecto de Nietzsche fá-lo descobrir a estrutura heraclítica do espírito alemão e o caminho da autodestruição desse espírito: o caminho de Goethe a Hegel; de Hegel ao "Estado de poder" prussiano e, ao mesmo tempo, a Marx, que é o precursor do grito apocalíptico de Nietzsche e o fundador do partido que fornece as massas disciplinadas do socialismo; o caminho, enfim, do nacionalismo e do socialismo à fusão de ambos no nacional-socialismo. A face exterior desse processo é a industrialização, o aburguesamento e a proletarização da Alemanha: fenômenos exteriores e, igualmente, fenômenos espirituais, que conduzem ao niilismo. É a autodestruição niilista no espírito de Nietzsche que o torna apto a reconhecer o niilismo alemão, o presente e o futuro.

A situação é cheia de contradições dialéticas. Nietzsche, o anticristo, fala como cristão a cristãos que já não o são. Nietzsche, o antialemão, fala como alemão a alemães que já não o são. Sozinho, ele está diante do nada. É o profeta do niilismo. Mas - o seu máximo feito profético - Nietzsche reconhece que a Alemanha precede, nesse caminho, aos outros povos e a toda Europa; que a situação alemã se tornará a situação do mundo. Di-lo o próprio Nietzsche: "Sou o profeta do niilismo europeu". 
O privilégio do profeta consiste em não ser entendido. $\mathrm{Na}$ Alemanha, não se sabia onde se estava; faziam-se retratos de Nietzsche à própria imagem, desde o nudismo e as reformas alimentárias até à "vontade de poder" do pangermanismo. $\mathrm{Na}$ Europa ocidental, porém, a situação espiritual era, de fato, outra: lá, era ainda possível o mal-entendido esteticista; quando descobriram o Nietzsche nacionalista, estavam na defesa; mas o próprio niilismo já tornou impossível a defesa eficaz contra o niilismo mais poderoso; enfim, uma jovem geração europeia, a dos Maulnier e Brasillach, saúda o niilismo de fora como a própria salvação. Os mal-entendidos, alemão e ocidental, de Nietzsche encontram-se, e isto faz ver que a situação alemã de então se tornara a situação europeia de hoje: a profecia cumpriu-se. Maravilhosamente, as anteriores oposições espirituais do "bom alemão" e do "bom europeu" desaparecem, e a sua inesperada congruência material ameaça o Continente com a destruição definitiva.

O desaparecimento da Europa seria a solução niilista da "questão alemã". A resistência contra essa solução é, primeiramente, a defesa desses valores da civilização alemã, sem os quais não haveria civilização europeia. Eis por que será impotente uma resistência que opõe às armas mecanizadas outras armas mecanizadas. $\mathrm{O}$ apelo só a essas armas trai aquele niilismo desesperado que Nietzsche denunciou, aquele estado de espírito que tolera a eliminação do espírito pela força material. Quem só toma a sério as armas já está perdido no espírito, e sê-lo-á também no campo de batalha. Cumpre tomar a sério a profecia de Nietzsche, reconhecendo a sua significação negativa. As profecias têm sempre uma significação negativa. Precisa-se percorrer em direção inversa o caminho de Nietzsche.

Nietzsche é, como Hegel, um espírito heraclítico. No tempo em que Nietzsche estreia, Hegel está quase esquecido na Alemanha. As diatribes anti-históricas de Schopenhauer haviam desacreditado o pensamento histórico de Hegel, que o positivismo 
Maria Carpeaux, O.

alemão desfigurara em sentido darwinista. Nietzsche, o discípulo de Schopenhauer, não conhece Hegel; mas protesta vivamente contra a identificação dos evolucionismos de Darwin e de Goethe, à qual chama um "crime de lesa-majestade". O heraclitismo de Nietzsche é um protesto inconsciente contra a falsa interpretação positivista de Hegel. Nietzsche lamentou, muitas vezes, a sua situação "a-histórica", de ter perdido a ligação histórica com o centro da civilização alemã, com Goethe. Perdera o sentido da dialética histórica, que é o que o ligaria a Goethe.

O "caminho para trás" é o caminho de Nietzsche a Hegel e de Hegel a Goethe. A dialética histórica do pensamento de Hegel é a congruência das contradições, a "coincidentia oppositorum" objetiva, que se tornou realidade subjetiva em Goethe. Foi um momento feliz do espírito alemão, e que passou. Recuperá-lo seria impossível sob a base do niilismo espiritual de Nietzsche. A única base possível era o niilismo político de Goethe, que, reconhecendo a caducidade do poder exterior, saudara em Napoleão o desmembrador da unidade alemã, o mensageiro do mundo ocidental; porque Goethe via na impotência material das unidades políticas a garantia do poder espiritual dos indivíduos nacionais. O tempo de Goethe é a idade de Péricles na história do espírito alemão. Em Goethe e Napoleão a congruência do "bom alemão" e do "bom europeu", a "coincidentia oppositorum", torna-se realidade espiritual. É a vida. A realidade material dessa congruência, de um ou de outro lado, seria a morte.

\footnotetext{
Abstract: In an attempt to understand the dilemma between the "values of the German civilization and the destructive forces within the same people that created them," the Austrian-born Brazilian literary critic Otto Maria Carpeaux refutes three theories held then and deems Nietzsche, the "Crucified Dionysus," as the one who experienced and anticipated the contradictory forces of the German spirit. After an analysis of the misunderstandings about Nietzsche's reception both in Germany and in Europe at large up to 1942, the author draws upon the thesis that the German thinker would be simultaneously a poet, a philosopher
} 
and a prophet, which could only be possible within a "homo religious," one who would experience the conflict arising from the old Norse barbarousness and that of the new German bourgeois class. Gifted with a "Heraclitically structured" intellect, such as that of Hegel, Nietzsche, however, in his position as the "prophet of European nihilism," would have discovered not only "the Heraclitic structure of the German spirit," but, above all, "the path to self-destruction of this spirit." That is, he would have anticipated "the path of nationalism and socialism up to their fusion into National-Socialism."

Keywords: Nietzsche - german spirit - conflict - nihilism - nazism. 